\title{
Monozygotic Monoamniotic Twin Pregnancy with TRAP Sequence and Acardiac Amorphous Foetus
}

\author{
Ruby Bhatia ${ }^{1}$, Sunita Mor ${ }^{2}$, Trisha Arora ${ }^{3}$, Bindiya Dave ${ }^{4}$, Unmesh Santpur ${ }^{5}$
}

\begin{abstract}
${ }^{1}$ Department of Obstetrics and Gynaecology, Maharishi Markandeshwar Institute of Medical Sciences and Research (Deemed to be University), Mullana, Ambala, Haryana, India. ${ }^{2}$ Department of Obstetrics and Gynaecology, Maharishi Markandeshwar Institute of Medical Sciences and Research (Deemed to be University), Mullana, Ambala, Haryana, India. ${ }^{3}$ Department of Obstetrics and Gynaecology, Maharishi Markandeshwar Institute of Medical Sciences and Research (Deemed to be University), Mullana, Ambala, Haryana, India. ${ }^{4}$ Department of Obstetrics and Gynaecology, Maharishi Markandeshwar Institute of Medical Sciences and Research (Deemed to be University), Mullana, Ambala, Haryana, India. ${ }^{5}$ Department of Obstetrics and Gynaecology, Maharishi Markandeshwar Institute of Medical Sciences and Research (Deemed to be University), Mullana, Ambala, Haryana, India.
\end{abstract}

\section{INTRODUCTION}

The 'Twin Reversed Arterial Perfusion (TRAP)' sequence or acardiac twinning, or chorioangiopagus parasiticus is an anomaly which is unique to the monochorionic multiple pregnancies and is a rare complication that affects around 1 in 100 monozygotic twin pregnancies and about 1 in 35,000 overall, with no recognized familial recurrence. ${ }^{[1]}$ They have almost doubled over the last two decades as a result of both the increasing average maternal age and with the increased use of assisted reproductive techniques. Physiologically, there is lack of a well-formed cardiac structure in one foetus (acardiac) that acts as a parasite as it is haemodynamically dependent on the structurally normal co-twin (pump twin) through a superficial artery-to-artery placental anastomosis. Various theories that explain the pathogenesis of the anomaly attribute it to either dysmorphogenesis or presence of arterio-arterial anastomosis, with latter being the most popular. ${ }^{[2]}$ In arterio-arterial anastomosis there is a reversal of blood flow from the umbilical artery of pump twin into umbilical artery of the perfused twin therefore bypassing the placenta, henceforth poorly oxygenated blood contributes to deficient development of the head, upper limbs, torso and heart while the better oxygenated blood flowing via umbilical artery through common iliac artery and aorta allows better development of the lower part of the body.[1]-[3]

Morphological types of acardiac twins-

- Acardius anephus presents with absence of the head, upper limbs and torso but with preservation of the lower limbs, genitalia and viscera. It is the most common type.

- Acardius anceps lacks even rudimentary heart and present with rudimentary cranial structures. It is the most developed type.

- Acardius amorphous comprises of an amorphous mass of bones, muscles, fat and connective tissues. It is the least differentiated type.

- Acardius acormus present with the head as the only developed structure while all other structures are essentially absent. It is the rarest type.[3],[4]
Corresponding Author:

Dr. Trisha Arora,

Hostel No. 9, Room No. 316,

Maharishi Markandeshwar University,

Mullana, Ambala-133207,

Haryana, India

E-mail: arora.trisha@gmail.com

DOI: $10.14260 /$ jemds/2020/14

Financial or Other Competing Interests: None.

How to Cite This Article:

Bhatia R, Mor S, Arora T, et al. Monozygotic monoamniotic twin pregnancy with trap sequence and acardiac amorphous foetus. J. Evolution Med. Dent. Sci. 2020;9(01):63-66, DOI: $10.14260 /$ jemds/2020/14

Submission 02-11-2019,

Peer Review 21-12-2019,

Acceptance 27-12-2019,

Published 06-01-2020. 
The diagnosis is made on ultrasonography by poorly differentiated head, trunk and upper extremities, or any abnormal cystic areas in the upper part of the body of the affected twin, and absence of identifiable cardiac pulsation. Doppler study is used for the demonstration of reversal of flow through the umbilical arteries to the affected foetus. If difference between the pump twin and the acardiac twin resistance index (RI) is more than 0.2 , it is associated with a good prognosis.[3] In $75 \%$ of cases the umbilical cord of the recipient twin contains a single umbilical artery.[3] Three dimensional sonography helps in the assessment of TRAP sequence, its extent and severity. Two-dimensional sonographic foetal weight estimation is not clinically applicable due to amorphous structures of the acardiac twin[5] hence the 3D sonographic body volume estimation is considered to be a better parameter for reflecting the size of a twin and can assist the management. In doubtful cases magnetic resonance imaging (MRI) can be offered.[6]

The major complicating factor is high-output congestive cardiac failure in the pump twin which occurs secondary to the strain of perfusing the acardiac twin that is the recipient twin. The high cardiac output leads to increased perfusion of the kidneys which causes over production of foetal urine and hence polyhydramnios.[3] If the weight of the acardiac twin is higher than pump twin the prognosis is worse. It was documented that when an acardiac/pump ratio is above $70 \%$ at birth, the incidence of preterm delivery is $90 \%$, polyhydramnios is $40 \%$ and congestive cardiac failure is $30 \% .^{[3]}$ Perinatal mortality rates up to $50 \%-75 \%$ have been reported.[7],[8] Twin reversed arterial perfusion (TRAP) syndrome is a rare condition $(0.3: 10,000$ births $)$ that occurs in monochorionic twin pregnancies, resulting in coexistence of a normal "pump" twin and an acardiac twin. The acardiac twin is dependent upon the normal twin to provide circulation by means of vascular anastomosis. The acardiac twin is a parasite, putting the pump foetus at risk of high output cardiac failure. Overall survival rate of pump twin is 50\%.

We present a rarest of rare case in a twenty-two-year-old unbooked primigravida at gestation $31^{+5}$ weeks whose ultrasound examination revealed monochorionic monoamniotic twin pregnancy with acardiac amorphous foetus B showing cystic hygroma with hydrops and normal foetus A with polyhydramnios. She underwent caesarean section and delivered first live normal foetus weighing 1.383 $\mathrm{kg}$ and second acardius amorphous weighing $2.5 \mathrm{Kg}$ extracted with great difficulty after increasing uterine incision. The monozygotic monochorionic monoamniotic twin pregnancy with TRAP with acardiac amorphous foetus B showing cystic hygroma and hydrops with normal foetus $\mathrm{A}$ as cephalic presentation on ultrasound examination. Caesarean Section was done and a live Fetus A with weight $1.383 \mathrm{Kg}$ was delivered as cephalic presentation and foetus B, acardiac twin with weight $2.5 \mathrm{~kg}$ was extracted with great difficulty after increasing uterine incision which showed features of TRAP. First case seen in 36 years of my clinical experience.

\section{PRESENTATION OF CASE}

A 22-year-old unbooked, primigravida with period of gestation $31^{+5}$ weeks, Hindu, housewife by occupation, matriculate presented to the outpatient department with twin pregnancy and USG showing monoamniotic monochorionic twins with $1^{\text {st }}$ foetus alive and corresponding to $31 \mathrm{wks}$. and second foetal demise. Patient had $1^{\text {st }}$ antenatal visit at 21 weeks of gestation with the private practitioner at Saharanpur and ultrasonography depicted twin pregnancy with first live foetus of gestation $21^{+2}$ weeks with no gross CMF and second dead foetus with massive oedema, hydrops foetalis. Trimester history was uneventful. Patient took folic acid, iron and calcium supplements. There was no family history of twin pregnancy on both sides and marriage was non consanguineous. She had no history suggestive of infections or any drug intake. She had her second visit at $31^{+2}$ weeks gestation with the same private practitioner and ultrasonography was done which showed monochorionic monoamniotic twin with first foetus of gestation 31 weeks and second acardiac foetus with hydrops foetalis.

Patient was moderately built woman. Vital signs were stable. Abdomen was overdistended, enlarged more for gestational age, tense, foetal parts could not be made out. Urgent ultrasound scan confirmed monochorionic monoamniotic twin pregnancy with normal foetus A corresponding to 31 weeks gestation with normal arterial and venous flow and foetus $\mathrm{B}$, acardius amorphous, large surrounded by marked diffuse subcutaneous oedema along its whole body with formation of large cystic areas. Head of foetus B shows ventricular dilatation with lateral ventricle of size 19 $\mathrm{mm}$. Chest and abdomen small, poorly differentiated. Cystic structure seen in foetal chest. Amniotic fluid maximum pocket was 6. Urinary bladder of foetus A distended and not visualized in foetus B. In foetus A left uterine artery Doppler RI was 0.5 and S/D ratio was 2 and in right uterine artery RI was 0.44 and $S / D$ ratio was 0.8 . There is single umbilical artery in foetus $B$ and no flow is seen in aorta. Features suggestive of normal foetus A and acardiac foetus B indicative of TRAP sequence.

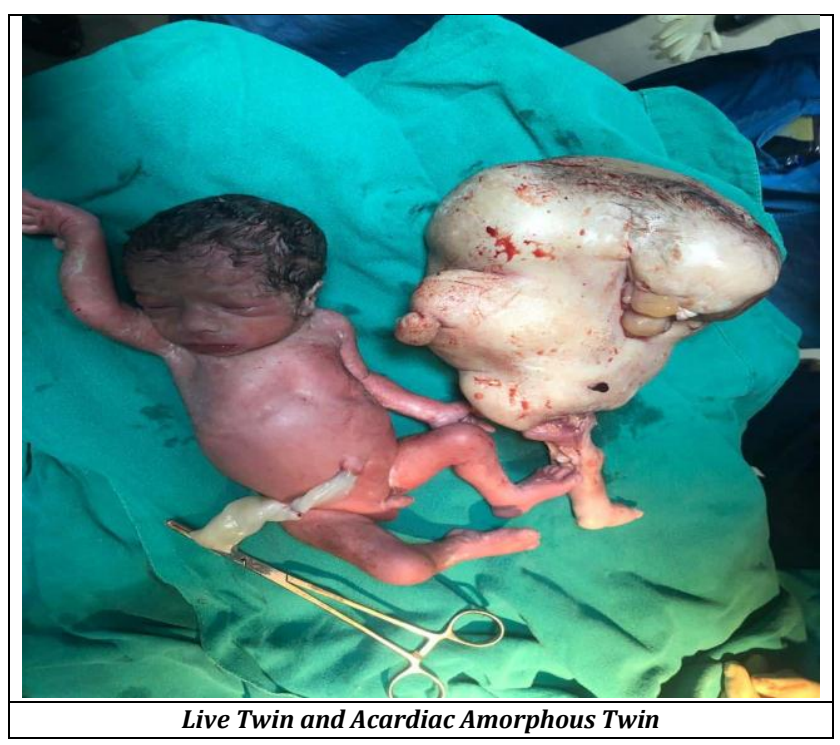

Caesarean section was done on 28/09/19. Intraoperative findings were excessive liquor drained, first twin was a live male baby, weighing $1383 \mathrm{~g}$ delivered as cephalic presentation, with APGAR scores of 6 and 8 in the first and fifth minute respectively and single monoamniotic monochorionic placenta. The second acardiac amorphous foetus was 
extracted with great difficulty after increasing uterine incision The second twin had amorphous head, upper torso and limbs with relatively well formed left lower limb. External genitalia were not differentiated. It weighed $2500 \mathrm{~g}$ that is more than normal foetus A. The umbilical cord of the acardiac twin was very short with single artery. The first twin was transferred to the special care baby unit. Normal twin male baby A was handed over to mother on day 17. Patient was discharged on day 11 with advice to follow up in post-natal clinic and wellbaby clinic.

\section{DISCUSSION}

The twin reversed arterial perfusion (TRAP) is a rare condition with a pump twin and a non-viable acardiac twin. The pump twin is at risks of complications such as prematurity, cardiac failure, hydrops and intrauterine demise. ${ }^{[9]}$ This condition is unique to monozygotic monochorionic twin gestations. The sequence can manifest as early as 11 weeks of gestational age. ${ }^{[9]}$ The diagnosis of TRAP is challenging. First trimester scan is necessary to determine the chorionicity and if done before 14 weeks gestational age has $100 \%$ sensitivity and $99 \%$ specificity.[1] $1^{\text {st }}$ USG was done at 21 weeks which showed monochorionic monoamniotic pregnancy with live foetus A and dead foetus $B$ with massive oedema suggestive of hydrops foetalis.

Management options are conservative, palliative and invasive treatment. The choice is dependent on the gestational age, size of acardiac twin, availability of a Paediatric surgeon, specialized equipment. Conservative management involves a close antenatal surveillance and timed delivery if there is any compromise in the pump twin.[9],[10] Palliative treatment involves prolongation of pregnancy by serial amnioreduction. The perinatal mortality from above treatments was reported to be $10 \%-55 \% .{ }^{[1],[9]}$

Invasive treatment involves interruption of blood flow to the acardiac twin using hysterotomy and selective delivery of the acardiac twin; embolization of the acardiac circulation by thromboembolic substances; foetoscopic cord ligation and ultrasound guided coagulation of the umbilical cord using laser or radiofrequency ablation. Hysterotomy along with selective delivery is no longer performed as it is associated with high maternal and foetal complications and due to less availability of invasive techniques.[11],[12] Percutaneous ultrasound guided intra-foetal alcohol injection is another technique and is inexpensive compared to endoscopic procedures.[11],[12] Ultrasound guided coagulation of the umbilical cord using laser or radiofrequency ablation can be performed as early as 16-24 weeks and is associated with survival rate of $80 \%$ - 88\%.[13],[14] High-intensity focused ultrasound (HIFU) treatment is a new non-invasive modality being used for treating cases of reversed arterial perfusion. It denaturates the foetal blood vessels using external ultrasound waves without direct foetal contact. However, such specialized equipment is only available in few centers around the world. ${ }^{[12]}$ Recurrence of TRAP sequence is unknown and is not increased, rather considered to be low and the couples can therefore be counselled optimistically for future pregnancy.[2]

\section{CONCLUSIONS}

Monozygotic pregnancy should be diagnosed early in first trimester. Monozygotic twin pregnancy with TRAP sequence should be referred early to tertiary care with availability of special foetomaternal unit for conservative or interventional management. Considerations should include the differences in foetal weight, amniotic fluid measurement and well-being of the pump foetus. Obstetrician, radiologist and paediatrician should all be well aware of this anomaly especially in twin/multiple pregnancies so that proper timely measures can be taken to survive the pump twin.

\section{REFERENCES}

[1] Liesbeth L, Deprest J. Fetal problems in multiple pregnancy. In: James DK, Steer PJ, Weiner CP, et al. eds. High risk pregnancy management options. $3^{\text {rd }}$ edn. Philadelphia: Elsevier Inc., 2006: p. 524-61.

[2] Prasad RHS, Prasad TR, Kumar KD. TRAP sequence-an interesting entity in twins. Journal of Clinical Imaging Science 2012;2:56.

[3] Chandramouly M, Namitha. Case series: TRAP sequence. The Indian Journal of Radiology \& Imaging 2009;19(1):81-3.

[4] Chanthasenanont A, Pongrojpaw D. TRAP Sequence in an acardiac twin. Journal of the Medical Association of Thailand 2007;90(4):819-22.

[5] Bornstein E, Monteagudo A, Dong R, et al. Detection of twin reversed arterial perfusion sequence at the time of first-trimester screening: the added value of 3dimensional volume and color Doppler sonography. Journal of Ultrasound in Medicine: official journal of the American Institute of Ultrasound in Medicine 2008;27(7):1105-9.

[6] Zeev B, Abdallah W, Onit SG, et al. Triplet gestationprevention, risk and management dilemmas. The Open Women's Health Journal 2008;2:11-21.

[7] Bavarian Sh, Sadidi S, Hassanzadeh P, et al. Acardiac parabiotic twin: a case report. Iran J Radiol 2007;4(4):251-3.

[8] Pandey K, Arya S, Kaitiyar G. A rare case of acardiac acephalus twin pregnancy. Journal of Obstetrics and Gynaecology of India 2010;60(1):75-6.

[9] Weisz B, Peltz R, Chayen B, et al. Tailored management of twin reversed arterial perfusion (TRAP) sequence. Ultrasound in Obstetrics and Gynecology: The Official Journal of the International Society of Ultrasound in Obstetrics and Gynecology 2004;23(5):451-5.

[10] Sullivan AE, Varner MW, Ball RH, et al. The management of acardiac twins: a conservative approach. American Journal of Obstetrics and Gynecology 2003;189(5):13103.

[11] Porreco RP. Percutaneous ultrasonographically guided ablation of an acardiac twin. American Journal of Obstetrics and Gynecology 2004;190(2):572-4. 
[12] Sepulveda W, Sfeir D, Reyes M, et al. Severe polyhydramnios in twin reversed arterial perfusion sequence: successful management with intrafoetal alcohol ablation of acardiac twin and amniodrainage. Ultrasound in Obstetrics and Gynecology: The Official Journal of the International Society of Ultrasound in Obstetrics and Gynecology 2000;16(3):260-3.

[13] Tsao K, Feldstein VA, Albanese CT, et al. Selective reduction of acardiac twin by radiofrequency ablation. American Journal of Obstetrics and Gynecology 2002;187(3):635-40.
[14] Okai T, Ichizuka K, Hasegawa J, et al. First successful case of non-invasive in-utero treatment of twin reversed arterial perfusion sequence by high-intensity focused ultrasound. Ultrasound in Obstetrics \& Gynecology 2013;42(1):112-4. 